\title{
Implementation of biocementation for a partially saturated problematic soil of the UK railway network
}

\author{
Muhammad Umair Safdar ${ }^{1}$, Maria Mavroulidou ${ }^{1, *}$, Michael J. Gunn ${ }^{1}$, Christopher Gray, Diane Purchase ${ }^{2}$, Jonathan \\ Garelick $^{3}$ and Ian Payne ${ }^{3}$ \\ ${ }^{1}$ London South Bank University, 103 Borough Road, SE1 0AA London, UK \\ ${ }^{2}$ School of Natural Sciences, Faculty of Science and Technology, Middlesex University, UK \\ ${ }^{3}$ Network Rail, UK
}

\begin{abstract}
This paper refers to biocementation of a problematic soil of the UK railway network as a potential stabilisation technique of this soil using indigenous ureolytic bacteria. The soil is peat, a soft foundation soil also subject to oxidation wastage. As the peat is under existing embankments, electrokinetics (EK) is proposed as a promising technique to implement treatments. In the context of unsaturated soils the paper thus focuses on two particular aspects relevant for the implementation of treatments and the stability of this soil, namely: a) the effect of degree of saturation of the peat on the bioelectrokinetic treatment ; b) the soil water retention curve of the soil affecting flow and transport; these are relevant as we focus on understanding and modelling the implementation of treatments through electrokinetics; moreover for the peat it is of importance to understand moisture exchange in the vadose zone and control groundwater table levels (e.g. during electrokinetics) in order to prevent further oxidation. After isolation and screening of indigenous microorgansisms Bacillus licheniformis was selected for further testing. The results in terms of unconfined compressive strength, $\mathrm{CaCO} 3$ content, swelling and compression behaviour and water retention proved the feasibility of biocementation using this indigenous microorganism. Ongoing work is assessing the required treated soil characteristics and related required biocementation degree to solve UK rail's peat foundation problems. Upscaling of the techniques towards in situ implementation is also planned in the next stage of the research.
\end{abstract}

\section{Introduction}

The aim of this research is to assess the feasibility of biocementation as a potential method of improving Peat Fens soil of the East Anglia railway network in the UK. This is a soft, unstable foundation soil of existing embankments, subject to oxidation wastage and settlements, which cause approximately $£ 900,000$ delay minute costs per mile for some of the worst sections.

Biocementation of soil is an emerging, novel technique, which has recently attracted the interest of researchers worldwide. It utilises the natural biological process of biomineralisation (the biological production of minerals through the metabolic processes of different types of microorganisms/plants) as a soil stabilisation method. It is proposed as a potentially more sustainable soil stabilisation technique, because the micro-organisms used are renewable, environmentally friendly and safe (non-pathogenic). When using biomineralisation as a soil stabilisation technique the most widely investigated process has been calcium carbonate precipitation to biocement sand with urea hydrolysing bacteria: following the pioneering works of Australian researchers [1-2], the vast majority of subsequent studies used the same ureolytic bacterium, Sporosarcina pasteurii, proven to be effective for biocementation (e.g. [3-5] amongst many others). Very few works extended the technique to different soils, namely silt (e.g. [6-9]), siltclay mixes [9], gravel [10] and peat [11]. The technique was also combined with electrokinetics (EK) to convey the substances in a fine-grained soil [12]. In EK an electric current is applied within the porous media to induce specific transport phenomena and give a more uniform flow distribution and control over the flow direction. For fine-grained soils and in particular under existing infrastructure, EK can be very useful in (a) effectively delivering chemicals or nutrients to indigenous bacteria in the soils for biostimulation or (b) introducing exogenous bacteria into the soil while enhancing bioavailability treatments. EK has been mainly applied as a contaminant remediation technology, also combined with bioremediation but to a lesser extent (e.g. [13-14]). Conversely using EK to convey treatments for geotechnical biocementation applications is rare (e.g. [12], [15]). Therefore, further research is required to take the technique to technical readiness level for industry adoption.

This paper thus focuses on the EK as a promising method of conveying the treatments under the existing embankments without pore pressure development and

Corresponding author: mavroum@1sbu.ac.uk 
with the potential of not affecting groundwater table levels (this is of primary importance to avoid further peat oxidation and wastage during treatment in case of falling groundwater levels and soil desaturation).

In the following sections the assessment of the treatments is based on unconfined compressive strength (UCS) testing, $\mathrm{CaCO}_{3}$ content (measured by acid digestion) and oedometer testing to assess post-treatment settlement reduction. Further targeted investigations focus on the effect of the degree of saturation on the success of the bioelectrokinetic treatment. In addition we perform chilled-mirror dewpoint technique testing to determine the Soil Water Retention Curves (SWRC) of the untreated vs. treated soil, which is of importance in order to understand moisture exchange in the vadose zone in response to groundwater table level changes.

\section{Materials and methods}

\subsection{Soil sample description}

The peat soil originated from two boreholes at an East Anglian railway site. Eighteen soil samples were used (nine from each borehole) from depths of $0-2 \mathrm{~m}$ with similar $\mathrm{pH}$, water and organic contents (average values of $7.15,55.5 \%$ and $51 \%$ respectively). The samples were described as dark brown, mostly amorphous, with a mixture of mineral and organic soil fractions. Fig 1 shows the particle size distribution of the portion of the soil sample retained for testing (passing $1.18 \mathrm{~mm}$ sieve) based on sieving, followed by hydrometer testing [16].

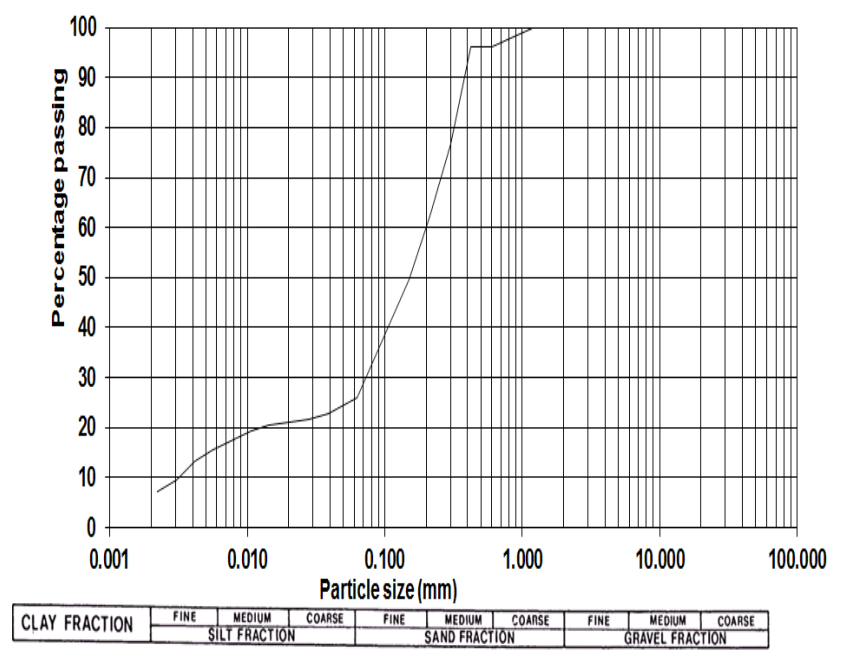

Fig. 1. Particle size distribution of the sample used.

\subsection{Microbiological study}

For bacteria isolation, $1 \mathrm{~g}$ of soil from each peat soil sample was diluted in sterile distilled water at the required dilution. The diluted soil solution was immediately plated out onto the agar plate: $1 \mathrm{~mL}$ of the diluted culture was plated out on $15 \mathrm{~mL}$ of Tryptic Soya Agar (TSA, Oxoid, UK), incubated at $25^{\circ} \mathrm{C}$ for 3-7 days. Samples that showed considerable growth at either 25 or $37^{\circ} \mathrm{C}$ (based on plate counting) were transferred to $\mathrm{B} 4$
Agar plates. B4 medium ( $\mathrm{pH} 7.3$ ) consists of $0.4 \%$ yeast extract, $0.5 \%$ dextrose, $0.25 \%$ calcium acetate and 1.4 $\%$ agar in solid preparations [17]. The strains were then incubated at $37^{\circ} \mathrm{C}$ for one week to form crystals. Colonies that showed good production of crystals as confirmed microscopically were selected and passaged twice on B4 plate to obtain purified single colonies. The selected strains were transferred to Nutrient Agar and Nutrient Broth (Oxoid, UK) for storage at $4{ }^{\circ} \mathrm{C}$ and $-80^{\circ} \mathrm{C}$ respectively. For the geotechnical analyses, all the test strains were cultivated at $\mathrm{pH} 7$ under aerobic batch conditions in a sterile culture medium of Nutrient Broth (Oxoid, UK) consisting of 5-g/L peptone, 5-g/L sodium chloride, 2-g/L yeast extract, and $1-\mathrm{g} / \mathrm{L}$ beef extract. Incubation was performed in a shaking incubator at 200 $\mathrm{rpm}$ and $37^{\circ} \mathrm{C}$. The strains were grown to an early stationary phase i.e., Optical Density (OD): OD600 ranging from $0.5-0.7$; they were then harvested by centrifuging at $8000 \mathrm{~g}$ for 10 minutes to achieve the final concentration of approximately $1 \times 10^{8} \mathrm{cfu} / \mathrm{mL}$ (optical density 3.3).

Enrichment for ureolytic bacteria and selection of isolates was followed by microbial identification and diagnosis using matrix-assisted laser desorption/ ionization time-of-flight/time-of-flight tandem mass spectrometry (MALDI-TOF/TOF MS) proteomic-based biotyping approach. Candidate strains for biocementation were then selected based on urease activity measured with a Urease Activity Assay kit (Colorimetric; Abcam, US). After unconfined compressive strength (UCS) testing (not shown here for brevity) the best strain i.e. Bacillus licheniformis was selected for further parametric study, which is ongoing (investigating treatment dosages and curing time effects); selected results of this study are included here.

\subsection{Treatments and implementation methods}

Two different implementation methods were used for the treatments, namely a pressure flow column setup (i.e. pressure driven flow through a soil column) and an EK set up. The apparatus used for the former method consisted of a Plexiglas cylindrical mould $(50 \mathrm{~mm}$ in diameter and $170 \mathrm{~mm}$ in length), a hydraulic pump, a compression frame and an effluent collector (Fig. 2). Sufficient water for the control sample or aqueous solution of Nutrient Broth for the biocementation samples of a total of $15 \%$ by mass of the soil sample was then supplied (this added \% was kept consistent for all samples). The soil was covered with air tight seal and left for 48-72 hours to attain homogeneity. Standard UCS specimens were then made from the soil sample by static compaction at a rate of $1 \mathrm{~mm} / \mathrm{min}$ to a dry density of $0.919 \mathrm{~g} / \mathrm{cm}^{3}$. The samples were transferred into the Plexiglas mould, where they were sandwiched between the two layers of perforated disks and filter papers (to avoid turbulent inflow and clogging at the inlet and outlet) and were mounted tightly onto the compression frame. The mould inlet was connected to the outlet of the pump. The cementing reagent solution was supplied into the specimen mould at a constant flow pressure of 150 
$\mathrm{kPa}$ (by regulating the pressure from the control panel of the pump) and at room temperature $\left(22-27^{\circ} \mathrm{C}\right)$ during 3 days; this was followed by variable curing duration (to select appropriate duration of curing). The $\mathrm{pH}$ and ammonium contents were monitored by sampling effluent from the sample.

For the EK method, a tank of $10 \mathrm{~mm}$ thick nonconductive acrylic 'Perpex' sheet with internal dimensions $210 \mathrm{~mm}$ length x $160 \mathrm{~mm}$ width x $140 \mathrm{~mm}$ depth was used. A purpose- built sample extractor internal layer was incorporated to prevent sample disturbance during extraction at the end of the test. The tank had perforated partition walls between the soil containing chamber and the electrolyte chambers of internal dimensions $100 \mathrm{~mm}$ length $\mathrm{x} 160 \mathrm{~mm}$ width $\mathrm{x}$ $140 \mathrm{~mm}$ depth (see Fig. 3). The dimensions of the cell allowed for extraction of duplicate UCS specimens (50 $\mathrm{mm}$ diameter and $100 \mathrm{~mm}$ height cylinders) from three different locations in the soil sample: namely from the areas next to the two electrolyte chambers and from the middle of the sample. A layer of filter paper was used on the perforated walls to prevent the movement of soil particles into the electrolyte chambers. Inert graphite sheet electrodes of $99 \%$ purity were used to eliminate electrode corrosion that would reduce the effectiveness of the system due to substantial voltage loss at the electrodes. The soil sample was compacted in the EK tank using a hydraulic compression frame in five equal layers to the required dry density of $0.919 \mathrm{~g} / \mathrm{cm}^{3}$ of the undisturbed soil. A constant voltage gradient of 0.4 $\mathrm{V} / \mathrm{cm}$ was maintained throughout the tests as recommended in the literature in order to prevent potential harm to the bacteria [18-19]. Periodic polarity reversal was applied every $24 \mathrm{~h}$, which is recommended for a better uniformity of the treatment but also to prevent high $\mathrm{pH}$ gradients that could be harmful to the bacteria [20]. To ensure that both voltage and $\mathrm{pH}$ did not change considerably during treatment, measurements of these quantities were performed at $0 \mathrm{~mm}, 50 \mathrm{~mm}$ and $100 \mathrm{~mm}$ away from the electrodes locations of the sample throughout the treatment; $\mathrm{pH}$ of the solutions was also monitored inside both electrolyte chambers during the treatment. In addition, temperature was recorded as this can affect bacteria growth.

The nutrient broth solution and the cementing reagents were supplied all in one single solution (divided equally in the two electrolyte compartments i.e.7.5\% per dry soil mass per compartment). The EK treatment lasted for two weeks, (i.e. 7 days per electrode polarity), followed by one additional day of curing, which is a typical field treatment length [e.g. 20] and was used here to prove the biocementation feasibility. Note that at this initial stage aiming at proving the feasibility of peat biocementation, the bacteria were mixed with the soil before the application of the EK treatment which was used to supply the nutrients and cementing reagents. However, in further planned tests the bacteria are also supplied electrokinetically consistently with the realistic field implementation of the treatment.

A number of control samples and samples with treatments with or without bacteria were prepared. Namely, in addition to testing the untreated soil statically recompacted at its original dry density of $0.919 \mathrm{~g} / \mathrm{cm}^{3}$ (see Table 1, Test ID: 'Natural'), EK samples with only water $(15 \%$ added water was applied to maintain similar moisture content conditions as the bacteria treated samples and hence avoid different moisture content effects), marked EK-water in Table 1, and finally soil samples treated with $15 \%$ per dry soil mass nutrient broth solution (of a $3 \mathrm{~g} / \mathrm{L}$ concentration) to exclude effects on strength (flocculation/binding of soil particles) from the salts contained in the nutrient solution (marked EK-nutrient in Table 1).

At the end of the tests, specimens for unconfined compressive strength (UCS), oedometer tests and soil water retention curve (SWRC) testing were cut from the respective samples. SWRC measurements were performed using a chilled-mirror dew-point potentiameter to measure total soil suction. Chilledmirror potentiameter apparatus uses the principle of thermodynamic relationship between relative humidity, temperature and total suction according to Kelvin's equation. The device thus computes the total suction based on the equilibrium of the liquid phase of the water in a soil specimen with the vapour phase of the water in the air space above the sample in a sealed chamber. The effect of the treatment was assessed based on the slope of the water content vs total suction curves: flat slopes would point at soils that are more prone to volume changes during suction changes [21].

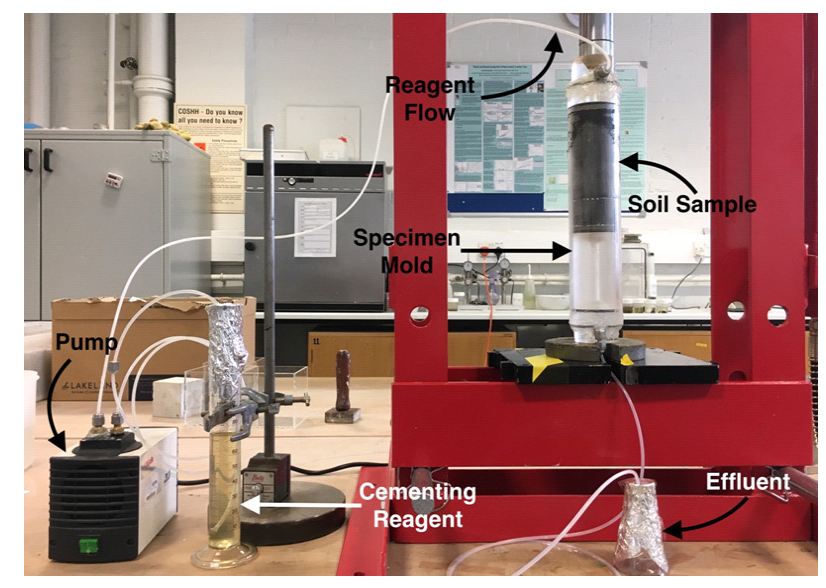

Fig. 2. Pressure flow column setup.

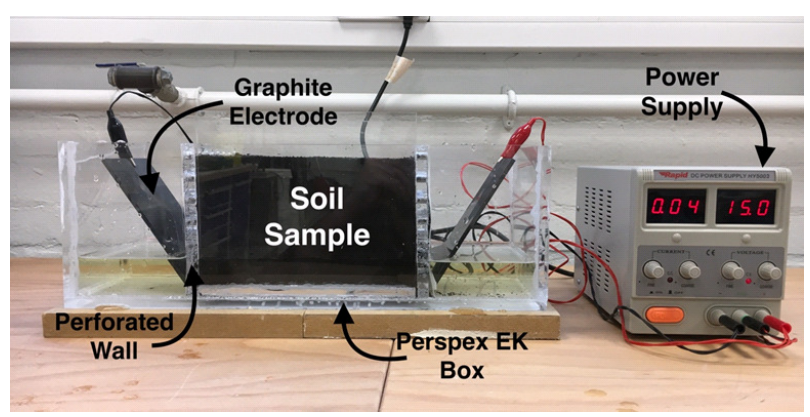

Fig. 3. Electrokinetic system setup. 


\section{Results and discussion}

\subsection{UCS testing}

Indicative UCS results with (treated) or without Bacillus licheniformis (B1) strain are shown in Table 1. All presented results used $\mathrm{B} 1$ populations of $1 \times 10^{8} \mathrm{cfu} / \mathrm{mL}$ supplied with equimolar solutions of calcium chloride and urea $(1 \mathrm{M}: 1 \mathrm{M})$. For the flow column results shown in this paper, cementing agent flushing during 3 days was followed by one day of curing; for EK 14 days of injection with polarity reversal were followed by one additional day of curing. Further results with different solution concentrations and curing durations can be found in [22]. All presented results used EK (electrokinetics) for treatment implementation except for the natural soil and the sample marked FlowCol-B1 originating from the flow column tests. For EK (r),(l),(m), refer respectively to right and left electrodes and middle of sample.

Table 1. Indicative UCS results of peat biocementation.

\begin{tabular}{|c|c|c|c|}
\hline Test ID & $\begin{array}{c}\text { Initial } \\
\text { Degree of } \\
\text { saturation, } \\
\mathbf{S}_{\mathrm{r}}(\%)\end{array}$ & $\begin{array}{c}\mathbf{q u}_{\mathrm{u}} \\
(\mathbf{k P a})\end{array}$ & $\begin{array}{c}\mathrm{CaCO}_{3} \\
(\%)\end{array}$ \\
\hline Natural Peat & 85 & 174 & 0.06 \\
\hline FlowCol-Bl & 85 & 380 & 0.91 \\
\hline EK-water & 95 & $\begin{array}{l}369(\mathrm{r}) \\
316(\mathrm{~m}) \\
374(\mathrm{l})\end{array}$ & $\begin{array}{l}0.19 \\
0.12 \\
0.21\end{array}$ \\
\hline EK-water & 85 & $\begin{array}{l}359(\mathrm{r}) \\
305(\mathrm{~m}) \\
347(\mathrm{l})\end{array}$ & $\begin{array}{l}0 . .20 \\
0.14 \\
0.19\end{array}$ \\
\hline EK-water & 75 & $\begin{array}{c}307(\mathrm{r}) \\
289(\mathrm{~m}) \\
301(\mathrm{l})\end{array}$ & $\begin{array}{l}0.1 \\
0.1 \\
0.1\end{array}$ \\
\hline EK-nutrient & 85 & $\begin{array}{l}378(\mathrm{r}) \\
320(\mathrm{~m}) \\
356(\mathrm{l})\end{array}$ & $\begin{array}{l}0.13 \\
0.13 \\
0.19\end{array}$ \\
\hline EK-B1 & 95 & $\begin{array}{c}471(\mathrm{r}) \\
363(\mathrm{~m}) \\
466(\mathrm{l})\end{array}$ & $\begin{array}{l}1.46 \\
1.21 \\
1.46\end{array}$ \\
\hline EK-Bl & 85 & $\begin{array}{l}458(\mathrm{r}) \\
412(\mathrm{~m}) \\
448(\mathrm{l})\end{array}$ & $\begin{array}{l}1.71 \\
1.16 \\
1.24\end{array}$ \\
\hline EK-Bl & 75 & $\begin{array}{c}344(\mathrm{r}) \\
307(\mathrm{~m}) \\
359(\mathrm{l})\end{array}$ & $\begin{array}{l}1.16 \\
0.96 \\
1.22\end{array}$ \\
\hline
\end{tabular}

For the peat microbially induced calcite precipitation was proven, as based on Table 1 UCS $\left(\mathrm{q}_{\mathrm{u}}\right)$ strengths increased and increased $\mathrm{CaCO}_{3}$ content was detected. EK (with polarity reversal) enhanced the strength compared to the untreated peat (even without the use of bacteria). Compared to Flow Column, EK combined with bacteria showed higher strengths and $\mathrm{CaCO}_{3}$ contents hence can be deemed to be more successful. The influence of degree of saturation on the EK results can be seen for both the EK treatment without bacteria and those with bacteria, with the success of the treatment generally increasing with increasing degrees of saturation (where strengths are higher). It is interesting that whereas for EK used without bacteria the increase in strength with degree of saturation is observed in all locations (with respect to the electrodes), when bacteria are used there is an exception to the rule in the middle of the sample, where the intermediate degree of saturation showed better results than the higher degree of saturation. This merits further investigation.

All treatments with bacteria show evidence of $\mathrm{CaCO}_{3}$ precipitation of the area of approximately $1 \%$ or more, as opposed to control samples without bacteria treatments.

\subsection{Oedometer testing}

Fig. 4 reports the compression results at different pressures for the untreated peat specimen and two indicative treated specimens cut from the pressure flow column samples $\left(1 \times 10^{8} \mathrm{cfu} / \mathrm{mL}\right.$ Bacillus licheniformis with cementing reagent solution of $1 \mathrm{M})$. The two saturated specimens (treated and untreated) were left to swell (free swelling) prior to compression at an applied pressure of $25-800 \mathrm{kPa}$ followed by unloading, whereas the unsaturated treated specimen was subjected to compression and unloading without initial saturation/swelling stage. It is notable that the saturated treated specimen swelled less than the saturated untreated one, indicating the beneficial effect of the treatment. It can also be seen that the bacteria treatment affected the compression behaviour of the specimen considerably reducing (but not eliminating) the compressibility of the peat soil. Concerning the comparative results of the unsaturated treated vs saturated treated specimens, the differences in the void ratios of the unsaturated treated and saturated treated specimens are due to the initial conditions prior to compression (i.e. free swelling vs compression starting at unsaturated state, hence no increase in the initial void ratio) but the gradients of both compression and swelling curves are practically the same. Both saturated and unsaturated specimen cross the untreated (zero suction) normal consolidation line but there is practically no difference between the unsaturated and saturated treated specimens indicating that the biocement bonding is the main factor controlling this behaviour rather than suction which is a known behaviour of cemented soils (e.g. [23]). 


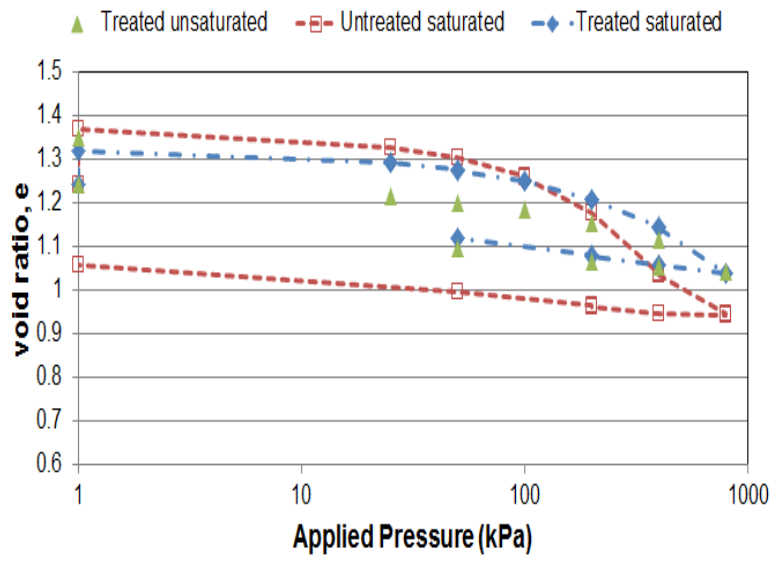

Fig 4. Oedometer testing results.

\subsection{SWRC results}

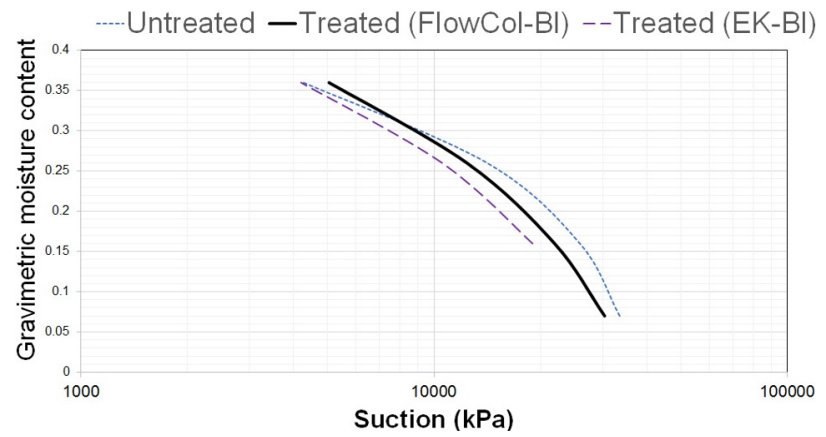

Fig 5. Indicative SWRC results for untreated and treated soils based on chilled-mirror dew point potentiometer.

Fig. 5 shows indicative preliminary SWRC results from chilled-mirror dew point potentiameter measurements (drying curves) in terms of gravimetric water content vs total suction. There is some indication of a small effect of the flow-column treatment on the macrostructure of the soil based on the initial portion of the curve that shows that the air entry value (the value of suction required for the soil to start draining) has increased slightly (probably due to some consolidation effect) but there is little effect on the rate of desaturation at higher suctions as shown by the slope of the curves. Also, the EK treated sample and the untreated sample have the same air entry value which would not be consistent with a reduction in the pore and throat size due to cementation. In general the treated soil curves plot below the untreated soil SWRC i.e. for the same water content lower suctions are required for the treated soils. It would have been expected that if calcite precipitation led to a decrease in the pore and pore throat size and also potentially some increase in the particle surface roughness (hence specific surface), both these factors would have led to a higher water retention at the same suction. However as argued in [24] there can be a competing effect of the changes in the double-layer thickness which could be the cause of the observed behaviour (a decrease in the double layer, which leads to lower matric suctions at the same fluid saturation). Overall however these first SWRC results imply that biocementation did not appear to have a major effect on the water retention of the soil, at least for the specific treatments and resulting calcite contents.

\section{Conclusions}

The results proved the feasibility of biocementation using indigenous microorganisms. This was proven in terms of treated soil properties (unconfined compressive strength, swelling and compression behaviour and water retention) as well as $\mathrm{CaCO}_{3}$ contents. Using indigenous non-pathogenic bacteria is environmentally beneficial, as the interference on the local microbial ecology is reduced compared to solutions using exogenous to the location bacteria. Ongoing work is assessing the required treated soil characteristics and related required biocementation degree to solve UK rail's peat foundation problems. The implementation methods are also further investigated and adjusted to reflect more closely the actual possible in situ implementation. In particular EK is actively investigated as a promising method of conveying the treatments under the existing embankments without pore pressure development and with the potential of not affecting groundwater table levels. Upscaling of the techniques towards in situ implementation is also planned in the next stage of the research.

\section{References}

1. Whiffin V.S. Microbial $\mathrm{CaCO} 3$ Precipitation for the production of Biocement, $\mathrm{PhD}$ thesis, (Murdoch University, Perth, Western Australia, 2004).

2. Al-Thawadi S.M. High strength in-situ biocementation of soil by calcite precipitating locally isolated ureolitic bacteria, $\mathrm{PhD}$ thesis (Murdoch University, Perth, Western Australia, 2008)

3. Al Qabany, A., Soga, K., and Santamarina, C.. J. Geotech. Geoenviron. Eng., 10.1061/ (ASCE) GT.1943-5606.0000666, 138 (992-1001) (2012).

4. Montoya B, DeJong J J Geotech Geoenviron Eng 141(6):04015019 (2015)

5. Gao Y, Hang L, He J., Chu J Acta Geotech. doi:10.1007/s11440-018-0729-3 (2018)

6. Rebata-Landa V. Microbial Activity in Sediments: Effects on Soil Behaviour, PhD Thesis (Georgia Institute of Technology, 2007)

7. Mortensen, B. M., Haber, M., DeJong, J. T., Caslake, L. F., and Nelson, D. C.. Appl. Microbiol., 111: (338-349) (2011)

8. Ng, W. S., Lee, M. L., Tan, C. K., and Hii, S. L.. J. Geotech. Geoenviron. Eng., 140: 04014006 (2014)

9. Mavroulidou M, Morgan N.L., Sibanda, T, Serumaga M., Bhamidimarri R. $12^{\text {th }}$ International Conference on Environmental Science and Technology, Rhodes, Greece, 4-8 September 2011, (A1210-A1217) (2011) 
10. Van der Star W.R.L., van Wijngaarden-van Rossum W.K., van Paassen L.A., van Baalen L.R., van Zwieten G XV European Conf. on Soil Mech. and Geotech. Engineering, 12-15 September, Athens, Greece, Anagnostopoulos et al (eds), 85-90 (2011)

11. Kawasaki S., Hata T. J. of GEOMATE, June, 2016, 10 (22):2071-2076 (2016)

12. Keykha H. A, Huat B.B.K, Asadi A., Geotech. Geol. Eng., 32: (739-747) (2014)

13. Lageman R, Godschalk MS. Electrochim. Acta; 52(10 SPEC. ISS.): (3449-3453) (2007)

14. Barba, S, Villaseñor, J, Cañizares, P, Rodrigo, M. Electrochim. Acta, 10.1016/j.electacta.2018.11.195 (2018).

15. Keykha, H. A., Mohamadzadeh, H., Asadi, A., Kawasaki, S. Geotech. Test. J. (2018)

16. British Standards Institution (BSI) Methods of test for Soils for civil engineering purposes (BSI, London, 1990)

17. E. Boquet, A. Boronat, A. Ramos-Cormenzana, Nature 246: (527-529) (1973)

18. Mizuno, A. and Hori, Y. IEEE Trans. Ind. Appl., 24: (387-394) (1988)

19. Hassan, I., Mohamedelhassan, E., Yanful, E.K. and Yuan, Z.-C. Advances in Microbiology (AIM), 6: (57-72) (2016).

20. Mena E., Villaseñor J., Cañizares P., Rodrigo M.A. Chemosphere, 146: (300-307) (2016)

21. McKeen, R. G., Proc. of the $7^{\text {th }}$ Int.Conf. on Expansive Soils, 3-5 Aug. 1992, 1: ( 1-6) (1992)

22. Mavroulidou M, Safdar MU, Gunn MJ, Gray C., Payne I., Garelick J., and Purchase D. $16^{\text {th }}$ International Conference on Environmental Science and Technology, Rhodes Greece 4-7 Sept 2019

23. Zhang X., Mavroulidou M. Gunn MJ En Geo 193: (320-336) (2015)

24. Saffari R., Nikooee E., Habibagahi G. and van Genuchten, M.T. J. Geotech. Geoenviron. Eng., 145(7): 04019028 (2019) 